\title{
The Level of Neuromuscular Coordination between Hearing Impairment Compared with the Healthy in Jordan
}

\author{
Adnan Alqaraan, Mousa Ahmad, Rami Hammad \\ Faculty of Physical Education, The University of Jordan, Amman, Jordan \\ Email: adnanalqaraan@gmail.com,mosahammad71@gmail.com,ramihammad37@gmail.com
}

How to cite this paper: Alqaraan, A., Ahmad, M., \& Hammad, R. (2018). The Level of Neuromuscular Coordination between Hearing Impairment Compared with the Healthy in Jordan. Advances in Physical Education, 8, 337-343.

https://doi.org/10.4236/ape.2018.84029

Received: September 4, 2018

Accepted: November 3, 2018

Published: November 6, 2018

Copyright (c) 2018 by authors and Scientific Research Publishing Inc. This work is licensed under the Creative Commons Attribution International License (CC BY 4.0).

http://creativecommons.org/licenses/by/4.0/

cc) (i) Open Access

\begin{abstract}
This study aimed to identify the level of neuromuscular coordination among the hearing impaired in Jordan and to identify differences in levels of neuromuscular coordination of the hearing impaired according to the variables of health status and gender. The descriptive method was used for its suitability to the nature of the study and its objectives. The sample population consisted of 159 individuals from different schools who were asked to participate voluntarily (72 with hearing impairments and 87 healthy). To measure neuromuscular coordination, the researchers used a test that measured hand-eye coordination (the steadiness tester) made by Lafayette Instrument, model 32011. They analyzed the results of the study using standard deviation and t-tests. The results of the study showed statistically significant differences between the level of neuromuscular coordination of males and female and this was shown by the presence of statistical significance which was $(p=$ $0.000)$ in the smallest hole ( 0.0625 inch). The results also showed that individuals with hearing impairments have superior neuromuscular coordination to healthy individuals. The study's main findings are that neuromuscular coordination of the hearing impaired is superior to that of healthy people; and that the neuromuscular coordination of females is superior to that of males. The researchers recommended employing the skills of the hearing impaired in sports requiring neuromuscular coordination (e.g. archery, darts, and billiards) because of the superior coordination of these individuals. They also recommended that gender differences be taken into account when designing training programs that depend on coordination and focus on motor skills.
\end{abstract}

\section{Keywords}

Hearing Impairment, Neuromuscular Coordination, Steadiness Test 


\section{Introduction}

The hearing impairment is the least prevalent among other disabilities comparing with visual, mental and physical disabilities, and it can be said that the prevalence rate is $0.05 \%$ and deaf prevalence rate is about $0.075 \%$, which means that among every 100 people there is a hearing-impaired person (Al-Azza, 2001).

The neuromuscular coordination plays an important and active role in various human movements in general and gains additional importance while learning and performing sports skills in particular, where the neuromuscular coordination shows the ability of central and peripherical nervous system in operation of holding and controlling or for repression of targeted motor units which required the accuracy and timing to motor performance (Khasawneh et al., 2009).

Magill (2011) identified the coordination among the multiple extremities, which is the ability to coordinate or compatibility among the movement of a group of extremities when they move at one time. While the compatibilities between eye and hand, eye and foot are one of the most important factors for the performance of the athlete, where there is a transmission of nerve signals between the nervous and muscular systems during the performance of individual sports movements, the neuromuscular coordination helps to perform motor skills required the vision and accuracy using either eye and hand or eye and foot. Also, there is a close relation between the coordination and balance, speed, agility and little as with force, but there is no relation with endurance as indicated both of (Spodek \& Saracho, 2006) as well as the coordination relation with age (Getchell \& Whitall, 2003), where the harmonic capabilities became weak as the person becomes older, as the coordination relation with growth especially bone growth like wrist and ankle bones, the bones of the ankle and wrist are less growing at birth, but at puberty age they grow fully. These bones are visible in females in the 51st month after birth while it is clear in the 66th month of age at birth of males.

This may be one of the reasons that explain the excellence of females in motor coordination more than males in the early stages of life according to a study (Johnston \& Williams, 2009), and also agrees what came out in the study of both (Khasawnah, Mousa, \& Atiyat, 2009). The excellence of females to males in the level of coordination is shown during the comparison between the preferred hand and the other hand. On the other hand, the coordination between eye and hand developed and the accuracy in the use of small muscles developed rapidly and distinctly in the age of (3 - 5) years (Sigelman \& Rider, 2009).

The hearing impairment is one of the sensory disabilities which impact on the Linguistic developmental manifestations, in addition to its impact on emotional and social growth. The definitions and perspectives on the concept of hearing disability have varied. Hearing impairment is seen in general as a concept that refers to an auditory loss ranging from simple to severe (Northern \& Downs, 2002), this concept involves two terms:

Deaf: A person with an auditory loss of about 70 Decibel or more (Moores, 
1996) and unable to recognize sounds in the surrounding environment even if the medical headset is used and he is also unable to benefit from hearing as a primary method of acquiring information (Smith, 2004).

As for the term of hard of Hearing: A person whose hearing loss ranges between 35 - $69 \mathrm{~dB}$ (Moores, 1996), the auditory residues are sufficient and capable-by using medical headset-to understand others and communicate with them orally (Smith, 2004).

\section{Methods and Material}

\section{Participants:}

The method used to compare between deaf and healthy is the t-test, which is a statistical hypothesis test utilized to analyze the comparison between the two groups (belonging from both genders, male and female) through two different samples when two normal distributions are unknown.

Participants study sample consists of 159 persons, 72 hearing impairment (males 32 \& females 40) aged between (13 - 22) means $=16.28$ and $\mathrm{SD}=1.680$, by percentage of $45 \%$. While the healthy samples 87 person - males $48 \&$ females 39 -aged between (13 - 19) means 16.84 and SD $=1.371$, by percentage of $55 \%$.

\section{Test Procedures:}

1) The work was divided into three parts:

a) First: person explains the skill to the hearing impaired;

b) Second: observation performance and timing;

c) Third: Data Recorder.

2) The examinee holds the sensitive pen with his favorite hand;

3) Each examinee has two trials, one experimental and the other as a test;

4) The examinee tries to stabilize the pen inside and the middle of the circle and holds for 10 seconds and then moves to the followed circle by the same time the previous circle;

5) The test ends after all the circles are finished.

\section{Steadiness Tester Hole Type used to assess Hand-eye coordination} (Figure 1).

The player's task is to hold a metal-tipped stylus in 9 progressively smaller hole sizes $(1.156 ; 1.125 ; 0.5 ; 0.312 ; 0.187 ; 0.109 ; 0.093 ; 0.078 ; 0.0625)$ inches
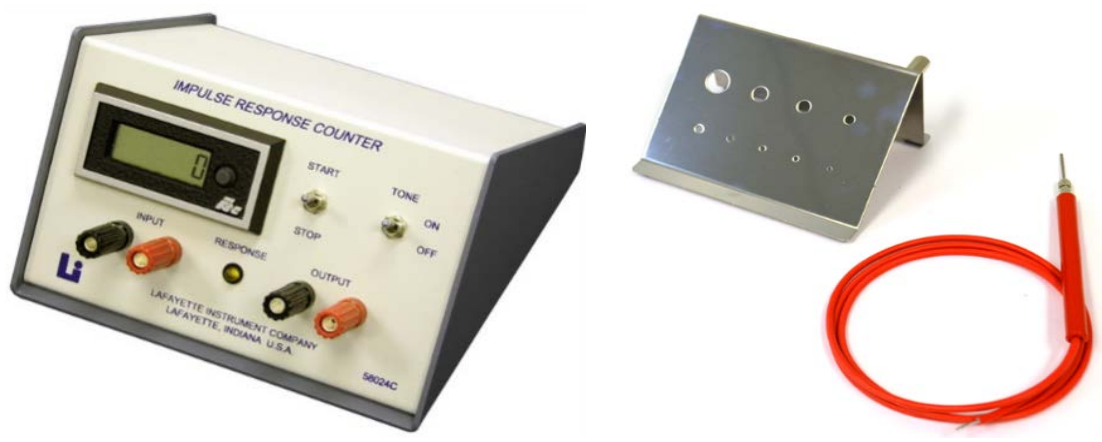

Figure 1. Hand-eye coordination manual dexterity. 
without touching the sides. Silent Impulse Counter Model 58024C used to detect errors.

Hand-eye coordination manual dexterity $10 \mathrm{~s}$ Measure by Steadiness Tester, Hole Type Model 32011.

\section{Results}

The figures in Tables 1-3 reflect the coordination performance for a set of healthy students at the different schools and Hearing-Impaired students performing coordination test. Coordination is expressed by the number of touches between the metal pen and the hole being the metal pen being centered through. As the number of touches increases over a specified time period the coordination is poor. The value zero indicates no touches consequently reflecting high coordination. As narrower the hole diameter as less, the coordination is and vice versa.

According to the probability values reflecting the significance of the comparisons results between healthy and deaf students mentioned it was clear that only two probability values were less than 0.05 , these two values were $(0.000)$ for the

Table 1. The coordination performance's mean's comparisons between healthy and deaf students using $t$ test.

\begin{tabular}{|c|c|c|c|c|c|c|}
\hline Hole Diameter (inch) & Group & $\mathrm{N}$ & M & SD & $\mathrm{T}$ & pro \\
\hline \multirow{3}{*}{1.156} & Healthy & 87 & 0.00 & 0.00 & \multirow{3}{*}{1.10} & \multirow{3}{*}{0.273} \\
\hline & & & & & & \\
\hline & Deaf & 72 & 0.01 & 0.12 & & \\
\hline \multirow{3}{*}{1.125} & Healthy & 87 & 0.03 & 0.18 & \multirow{3}{*}{0.91} & \multirow{3}{*}{0.363} \\
\hline & & & & & & \\
\hline & Deaf & 72 & 0.10 & 0.61 & & \\
\hline \multirow{3}{*}{0.5} & Healthy & 87 & 0.09 & 0.33 & \multirow{3}{*}{0.54} & \multirow{3}{*}{0.590} \\
\hline & Donf & 77 & 013 & 0,44 & & \\
\hline & Deat & 12 & 0.13 & 0.44 & & \\
\hline \multirow[b]{2}{*}{0.312} & Healthy & 87 & 0.29 & 1.15 & \multirow[b]{2}{*}{1.67} & \multirow[b]{2}{*}{0.097} \\
\hline & Deaf & 72 & 0.63 & 1.40 & & \\
\hline \multirow{3}{*}{0.187} & Healthy & 87 & 1.72 & 4.00 & \multirow{3}{*}{1.23} & \multirow{3}{*}{0.217} \\
\hline & & & & & & \\
\hline & Deaf & 72 & 2.54 & 4.30 & & \\
\hline \multirow{3}{*}{0.109} & Healthy & 87 & 2.46 & 3.60 & \multirow{3}{*}{4.51} & \multirow{3}{*}{$0.000^{*}$} \\
\hline & & & & & & \\
\hline & Deaf & 72 & 7.25 & 9.08 & & \\
\hline \multirow{3}{*}{0.093} & Healthy & 87 & 7.98 & 6.76 & \multirow{3}{*}{1.23} & \multirow{3}{*}{0.220} \\
\hline & & & & & & \\
\hline & Deaf & 72 & 9.71 & 10.80 & & \\
\hline \multirow{2}{*}{0.078} & Healthy & 87 & 18.83 & 10.02 & \multirow{2}{*}{1.02} & \multirow{2}{*}{0.309} \\
\hline & Deaf & 72 & 16.82 & 14.67 & & \\
\hline \multirow{3}{*}{0.0625} & Healthy & 87 & 34.83 & 14.09 & \multirow{3}{*}{4.20} & \multirow{3}{*}{$0.000^{\star}$} \\
\hline & & & & & & \\
\hline & Deaf & 72 & 24.76 & 16.09 & & \\
\hline
\end{tabular}

${ }^{*}$ In this case the result of the comparison in the statistical indication reflects a significance of the results since the values are below to 0.05 . 
A. Alqaraan et al.

Table 2. The coordination performance's mean's comparisons between healthy and deaf MALE students using $t$ test.

\begin{tabular}{|c|c|c|c|c|c|c|}
\hline Hole diameter (inch) & Group & $\mathrm{N}$ & M & $\mathrm{SD}$ & $\mathrm{T}$ & Pro \\
\hline \multirow{2}{*}{1.156} & Healthy & 48 & 0.00 & 0.00 & \multirow{2}{*}{-} & \multirow{2}{*}{-} \\
\hline & Deaf & 32 & 0.00 & 0.00 & & \\
\hline \multirow{2}{*}{1.125} & Healthy & 48 & 0.06 & 0.24 & \multirow{2}{*}{1.44} & \multirow{2}{*}{0.153} \\
\hline & Deaf & 32 & 0.00 & 0.00 & & \\
\hline \multirow{2}{*}{0.5} & Healthy & 48 & 0.15 & 0.41 & \multirow{2}{*}{1.02} & \multirow{2}{*}{0.307} \\
\hline & Deaf & 32 & 0.06 & 0.25 & & \\
\hline \multirow{2}{*}{0.312} & Healthy & 48 & 0.48 & 1.52 & \multirow{2}{*}{0.24} & \multirow{2}{*}{0.809} \\
\hline & Deaf & 32 & 0.41 & 0.95 & & \\
\hline \multirow{2}{*}{0.187} & Healthy & 48 & 2.90 & 5.06 & \multirow{2}{*}{0.23} & \multirow{2}{*}{0.817} \\
\hline & Deaf & 32 & 2.63 & 5.16 & & \\
\hline \multirow{2}{*}{0.109} & Healthy & 48 & 3.02 & 4.22 & \multirow{2}{*}{3.09} & \multirow{2}{*}{$0.003^{*}$} \\
\hline & Deaf & 32 & 8.38 & 10.86 & & \\
\hline \multirow{2}{*}{0.093} & Healthy & 48 & 8.35 & 7.40 & \multirow{2}{*}{1.47} & \multirow{2}{*}{0.144} \\
\hline & Deaf & 32 & 11.53 & 11.85 & & \\
\hline \multirow{2}{*}{0.078} & Healthy & 48 & 17.85 & 10.32 & \multirow{2}{*}{0.44} & \multirow{2}{*}{0.659} \\
\hline & Deaf & 32 & 19.28 & 18.45 & & \\
\hline \multirow{2}{*}{0.0625} & Healthy & 48 & 29.94 & 13.11 & \multirow{2}{*}{0.59} & \multirow{2}{*}{0.552} \\
\hline & Deaf & 32 & 27.78 & 19.18 & & \\
\hline
\end{tabular}

${ }^{*}$ In this case the result of the comparison in the statistical indication reflects a significance of the results since the values are below to 0.05 .

Table 3. The coordination performance's mean's comparisons between healthy and deaf FEMALE students using t test.

\begin{tabular}{|c|c|c|c|c|c|c|}
\hline Hole Diameter (inch) & Group & $\mathrm{N}$ & M & $\mathrm{SD}$ & $\mathrm{T}$ & pro \\
\hline \multirow{2}{*}{1.156} & Healthy & 39 & 0.00 & 0.00 & \multirow{2}{*}{0.98} & \multirow{2}{*}{0.327} \\
\hline & Deaf & 40 & 0.03 & 0.16 & & \\
\hline \multirow{2}{*}{1.125} & Healthy & 39 & 0.00 & 0.00 & \multirow{2}{*}{1.34} & \multirow{2}{*}{0.183} \\
\hline & Deaf & 40 & 0.18 & 0.81 & & \\
\hline \multirow{2}{*}{0.5} & Healthy & 39 & 0.03 & 0.16 & \multirow{2}{*}{1.63} & \multirow{2}{*}{0.107} \\
\hline & Deaf & 40 & 0.18 & 0.55 & & \\
\hline \multirow{2}{*}{0.312} & Healthy & 39 & 0.05 & 0.22 & \multirow{2}{*}{2.78} & \multirow{2}{*}{$0.007^{\star}$} \\
\hline & Deaf & 40 & 0.80 & 1.67 & & \\
\hline \multirow{2}{*}{0.187} & Healthy & 39 & 0.28 & 0.86 & \multirow{2}{*}{3.77} & \multirow{2}{*}{$0.000^{*}$} \\
\hline & Deaf & 40 & 2.48 & 3.53 & & \\
\hline \multirow{2}{*}{0.109} & Healthy & 39 & 1.77 & 2.52 & \multirow{2}{*}{3.67} & \multirow{2}{*}{$0.000^{*}$} \\
\hline & Deaf & 40 & 6.35 & 7.38 & & \\
\hline \multirow{2}{*}{0.093} & Healthy & 39 & 7.51 & 5.93 & \multirow{2}{*}{0.40} & \multirow{2}{*}{0.688} \\
\hline & Deaf & 40 & 8.25 & 9.78 & & \\
\hline \multirow{2}{*}{0.078} & Healthy & 39 & 20.03 & 9.64 & \multirow{2}{*}{2.26} & \multirow{2}{*}{$0.026^{\star}$} \\
\hline & Deaf & 40 & 14.85 & 10.59 & & \\
\hline \multirow{2}{*}{0.0625} & Healthy & 39 & 40.85 & 13.01 & \multirow{2}{*}{6.35} & \multirow{2}{*}{$0.000^{\star}$} \\
\hline & Deaf & 40 & 22.35 & 12.87 & & \\
\hline
\end{tabular}

${ }^{\star}$ In this case the result of the comparison in the statistical indication reflects a significance of the results since the values are below to 0.05 . 
coordination performance hole with diameter (0.109 inch) and (0.000) for the coordination performance through the hole with diameter $(0.0625)$. The coordination differences recorded on these two holes indicate that the coordination of healthy students was better than deaf students on the hole (0.109 inch) while the coordination of deaf students was better than healthy students when performing on the hole $(0.0625)$. The other probabilities were $>0.05$ suggesting no significant differences between healthy and deaf.

The researchers find that the disorder at the hearing impairment is less than the healthy persons and the concentration and attention levels for the hearing impairment is high, so they have more activity by using the other senses.

- Differences in coordination between healthy and deaf MALE students

According to the probability values reflecting the significance of the comparisons results between healthy and deaf MALE students mentioned it was clear that only the probability value related to the coordination differences on hole diameter ( $0.109 \mathrm{inch})$ was less than 0.05 . The coordination differences recorded on hole (0.109 inch) indicate that the coordination of healthy male students was better than deaf students. The other probabilities were $>0.05$ suggesting no significant differences between healthy and deaf students.

- Differences in coordination between healthy and deaf FEMALE students.

According to the probability values reflecting the significance of the comparisons results between healthy and deaf FEMALE students mentioned it was clear that the comparisons on holes (0.312 inch), (0.187 inch), (0.109 inch), (0.078 inch) and (0.0625 inch) probabilities values were less than 0.05 , these value were (0.007), (0.000), (0.000), (0.026) and (0.000) respectively. The differences recorded indicate that the coordination of healthy female students was better than deaf students on holes with diameters (0.312 inch), (0.187 inch) and (0.109) while the coordination of the deaf females' students was better on holes with diameters $(0.078 \mathrm{inch})$ and $(0.0625 \mathrm{inch})$. The other probabilities were $>0.05$ suggesting no significant differences between healthy and deaf female students.

The researcher find that the results of the study is compatible with (Johnston \& Nahmed, 2009) and (Alawamleh \& Almansi, 2014) that the females is more compatible of the males, because the females used the acuity skills such as Sucher draw and cooking in the early stages, which developing the sensorimotor coordination in (Cortex area).

\section{Conclusion}

Based on the discussion of the results, the researchers find that the level of neuromuscular coordination of hearing impaired is higher than that of the healthy in the most difficult circle, and level of neuromuscular coordination in females is higher than that of males.

\section{Recommendations}

Through the conclusions of the study, the researchers developing several recommendations are employing the abilities of the hearing impaired because they 
have a preference in neuromuscular coordination in sports which requiring neuromuscular coordination (shooting, arrows, and billiards), in addition to considering the individual differences between the Genders in training programs that depend on compatibility and focus in the design of motor skills, as well as conducting a standard and testing test in the Hashemite Kingdom of Jordan, also, conducting scientific studies to find out the causes of differences between males and females in neuromuscular coordination and finally conducting scientific studies showing the differences in neuromuscular coordination of the hearing impaired and other disabilities.

\section{Acknowledgements}

We would like to thank the Ministry of Education, Al-Amal Secondary Mixed School for the deaf, Al-Hassad Al-Tarbawi Schools for a grant to support this research and the University of Jordan, Faculty of Physical Education.

\section{Conflicts of Interest}

The authors declare no conflicts of interest regarding the publication of this paper.

\section{References}

Alawamleh and Almansi (2014). A Comparative Study to Identify the Individual Differences Related to the Cognitive Abilities of the Motor According to the Variables of Gender and Hand Used Journal of the University of Jordan, Studies of Educational Sciences ( $2^{\text {nd }}$ ed., pp. 41). Abingdon-on-Thames: Routledgem.

Al-Azza, S. (2001). Special Education for People with Disabilities: Intellectual Disabilities, Visual, Hearing Impairment and Movement Disabilities, (E 1). Amman, Jordan: Dar $\mathrm{Al}$-Sisi International.

Getchell, N., \& Whitall, J. (2003). How Do Children Coordinate Simultaneous Upper and Lower Extremity Tasks? The Development of Dual Motor Task Coordination. Journal of Experimental Child Psychology, 85, 120-140. https://doi.org/10.1016/S0022-0965(03)00059-6

Johnston, J., \& Williams, L. (2009). Early Childhood Studies. New York: Pearson Longman.

Khasawneh, A., Mousa, A., \& Atiya, K. (2009). Evaluating Neuromuscular Coordination for Hands among Physical Education Students. The Shield, 4, 44-59.

Magill, R. A. (2011). Motor Learning and Control: Concepts and Applications ( $9^{\text {th }}$ ed., pp. 4). New York: McGraw-Hill.

Moores, D. (1996). Education the Deaf: Psychology, Principles and Practices (4th ed.). Boston: Houghton Mifflin Company.

Northern, J., \& Downs, P. (2002). Hearing in Children. Philadelphia: Lipimcott Williams and Wilkins.

Sigelman, C. K., \& Rider, E. A. (2009). Life-Span Human, Development (6 ${ }^{\text {th }}$ ed.). Belmont, CA: Wadsworth Cengage Learning.

Smith, D. (2004). Introduction to Special Education: Teaching in an Age of Opportunity (5th ed.). Boston: Allyn and Bacon.

Spodek, B., \& Saracho, O. N. (2006). Handbook of Research on the Education of Young Chidren (2nd ed., pp. 117). Abingdon-on-Thames: Routledgem. 